\title{
Surface Modification and Application of Mordenite for the Removal of Metals as Oxoanions from Waste Water
}

\author{
VANDANA KUSHWAH $^{1 *}$, PRIYANKA SAHU ${ }^{2}$ and RASHMI TOMAR ${ }^{3}$ \\ ${ }^{1,2,3}$ Department of Chemistry, 475001, India. \\ ${ }^{*}$ Corresponding author E-mail: Vandvs72@gmail.com
}

http://dx.doi.org/10.13005/ojc/330454

(Received: March 30, 2017; Accepted: May 29, 2017)

\begin{abstract}
In this article, the sorption process of $\mathrm{Cr}$, As and $\mathrm{V}$ as oxoanions using modified mordenite zeolite as sorbent has been experimentally estimated. The sample of mordenite zeolite was synthesized and modified and batch method was employed for analysis. Parameters such as sorbent dose, concentration of metal oxoanions in solution ranging from 50 to $5 \mu \mathrm{g} /$ and effect of contact time were studied. Equilibrium concentration of chromate $\mathrm{Cr}(\mathrm{VI})$, arsenate $\mathrm{As}(\mathrm{V})$ and vanadate $\mathrm{V}$ (V) was estimated by spectrophotometer. The sorption kinetics of $\mathrm{Cr}$, As, $\mathrm{V}$ has been analyzed also. An equilibrium time of 6-7 $\mathrm{h}$ was required to establish equilibrium. The percentage sorption efficiency was determined for the system as a function of sorbate concentration. The maximum sorption ability of modified mordenite zeolite was found $74 \%, 88 \%$ and $98 \%$ for $\mathrm{Cr}$, As and $\mathrm{V}$ respectively. Results showed that surface modified mordenite zeolites hold great potential to remove selected oxoanion of heavy metal species from wastewater. It was also noticed that sorption was better for chromate as compared to other selected metals. The experiments included studies on sorption mechanism (sorption or ion-exchange) and sorption equilibrium. The ion exchange was the dominating mechanism of sorption with modified zeolite.
\end{abstract}

Keywords: Mordenite zeolite, SMZ, Chromate, Vanadate, Arsenate, Sorption

\section{INTRODUCTION}

Most of the industries discharge wastewater and their effluents containing toxic materials into rivers without adequate treatment. The presence of heavy metals in waste water constitutes one of the most important problems due to their high toxicity and cumulative character ${ }^{1}$. The industrial use of heavy metals has increased at a rapid rate in the modern era but have became a cause of concern due to their toxicity to human being and also for flora and fauna ${ }^{2}$.

Heavy metals such as lead, chromium, mercury, uranium, selenium, zinc, arsenic, cadmium, silver, gold, vanadium and nickel are often classified as potential. Most of the metals are highly toxic even in trace concentration. The toxicity of metal pollution 
is slow and interminable, as these metal ions are non bio-degradable and tend to accumulate in living organism causing various disease and disorder ${ }^{3-7}$.

Chromate is one of the most toxic environment pollutants. Its compounds are used in industrial application including metal plating, leather tanning and dye manufacture. In the past, it has also been added to course waters used for cooling towers because it was measured an inexpensive corrosion inhibitor. The two major forms found in the environment are hexavalent $\mathrm{Cr}$ (VI) and trivalent $\mathrm{Cr}$ (III) species. Large doses of $\mathrm{Cr}$ (VI) have been linked to cancer, skin ulcers, and other maladies ${ }^{8-}$ 10. The presence of arsenic in water is due to the dissolution of minerals from subterranean strata or from an anthropogenic origin such as the leaching of manmade arsenic compounds from smelting of metal ores, agricultural pesticides, desiccants and wood preservatives. The occurrence of arsenic in water provisions has been linked to arsenical skin cancer, dermatitis ${ }^{11}$, neurological effects, enlargement of liver, heart disease and internal cancers ${ }^{12}$.

Vanadate which is a highly toxic metal, has wide spread industrial applications used as steeladditives, vanadium steel alloys are very tough and are used for armours plate axles, tools piston rods and crank shafts. Vanadium used in nuclear reactor because of vanadium low neutron -absorbing properties. Vanadium has a number of effects on human health. When the uptake is too high, it can cause bronchitis and pneumonia. The acute effects of vanadium are irritation of lungs, throat eyes and nasal cavities, damage nervous system.

Numerous technologies have been developed for the removal of heavy metal contamination, in aqueous medium or in soils. Ionexchange and adsorption are amongst the most referred processes for this treatment ${ }^{13}$. The use of zeolite is one of the efficient and economical methods as proposed by some author for the treatment of heavy metal. Zeolites are hydrated alumino silicates consisting of three-dimensional networks of $\mathrm{SiO}_{4}$ and $\mathrm{AlO}_{4}$, linked by their oxygen atoms. Zeolites are characterized by high specific surface area and shows superior sorption and hydraulic properties and found use as molecular sieve, and sorbent for waste treatment. Zeolites have a negative charge compensated by the presence of exchangeablenative cations such as calcium, sodium, magnesium, potassium, among others ${ }^{14}$. These structures provide the material with multiple properties that make them useful for industrial applications where they can be modified for adsorption, ion exchange and catalytic processes $^{15}$.

Surface modification of zeolite with different organic groups is a powerful technique for tuning zeolite properties. Use surfactants to modify the surface of zeolite and thus produced surfactant modified zeolite. The primary monolayer is created by cationic exchange at the surface of zeolite, while the bilayer is produced through hydrophobic interactions ${ }^{16-17}$. The bilayer is stabilized at equilibrium by counter ions. The establishment of a stable bilayer gives the zeolite anionic exchange capabilities. Diverse types of cationic surfactants are available and have been tested on zeolite. Most commonly used in the past was the surfactant hexadecyltrimethylammonium (HDTMA), which belongs to the imadizolium group of green solvents, is more stable and is considered as more environmentally friendly.

In these work analogues of zeolitemordenite was successfully synthesized from sodium aluminates sodium hydroxide and silica solution. Zeolite modified by hexadecyltrimethylammonium (HDTMA) modified mordenite was investigated for their ability to absorb various metal oxoanion.

\section{MATERIALS AND METHODS}

\section{Zeolite source}

Analogue of Mordenite zeolite $\left(6 \mathrm{Na}_{2} \mathrm{O}\right.$ : $\mathrm{Al}_{2} \mathrm{O}_{3}: 30 \mathrm{SiO}_{2}: 780 \mathrm{H}_{2} \mathrm{O}$ ) was used for present studies which was synthesized using source material; Distilled water, Sodium hydroxide, Sodium aluminates, Silica.

\section{Synthesis of Analogue of Mordenite zeolite:}

The Mordenite with a Si/Al ratio of 9 was synthesized by hydrothermal method according to IZA synthesis commission of zeolite. The preparation of zeolite was carried out in a two step process-in first process Sodium Aluminates as the aluminum source was mixed with an aqueous solution of Sodium Hydroxide, then Silica (Otto chemika) was added to the mixture. To obtain the fine particle and complete 
mixing of gel, the gel solution is magnetically stirred for $30 \mathrm{~min}$. on magnetic stirrer. In the second step process, the resultant mixture is immediately transferred in a $100 \mathrm{ml}$ Teflon lined stainless steel pressure vessel (PARR make) kept in preheated oven at autogenous pressure and static-condition and crystallization was carried out at $443 \mathrm{~K}$ under autogenous pressure without agitation for 24 hours. After completion of synthesis period the product was recovered by filtration, washed thoroughly with deionized water and dried at $373 \mathrm{~K}$ overnight and kept in powder form for further use.

\section{Surface Modification of Mordenite Zeolite}

Synthesized raw zeolite was treated with HDTMA- Br (Hexadecyltrimethylammonium Bromide), surfactant to make it capable to exchange anion. $5 \mathrm{~g}$ of mordenite zeolite was mixed with 2.5 gm of hexadecyltrimethylammonium (HDTMA) and $180 \mathrm{ml}$ deionized water was added to it. Mixture was

Table1: Effect of time on sorption of metal oxoanions by surfactant modified Mordenite

\begin{tabular}{|c|c|c|c|c|}
\hline $\begin{array}{l}\text { Metal } \\
\text { oxoanions }\end{array}$ & $\begin{array}{l}\text { Contact time } \\
\text { in minutes }\end{array}$ & $\begin{array}{l}\text { Initial } \\
\text { concentration }\end{array}$ & $\begin{array}{l}\text { concentration at } \\
\text { equilibrium }\end{array}$ & $\begin{array}{l}\text { Sorption } \\
\%\end{array}$ \\
\hline & 5 & 4.446 & 2.706 & 39.12 \\
\hline & 10 & 4.446 & 2.288 & 48.54 \\
\hline & 15 & 4.446 & 1.512 & 65.97 \\
\hline & 30 & 4.446 & 1.398 & 68.57 \\
\hline & 60 & 4.446 & 1.274 & 71.34 \\
\hline \multirow[t]{11}{*}{$\mathrm{CrO}_{4}^{2-}$} & 120 & 4.446 & 1.150 & 74.13 \\
\hline & 180 & 4.446 & 1.011 & 77.24 \\
\hline & 240 & 4.446 & 0.959 & 78.41 \\
\hline & 360 & 4.446 & 0.910 & 79.51 \\
\hline & 420 & 4.446 & 0.796 & 79.57 \\
\hline & $24 \mathrm{~h}$ & 4.446 & 0.914 & 79.44 \\
\hline & 5 & 1.253 & 0.986 & 21.29 \\
\hline & 10 & 1.253 & 0.878 & 29.92 \\
\hline & 15 & 1.253 & 0.802 & 35.99 \\
\hline & 30 & 1.253 & 0.776 & 38.06 \\
\hline & 60 & 1.253 & 0.725 & 42.13 \\
\hline \multirow[t]{6}{*}{$\mathrm{AsO}_{4}{ }^{2-}$} & 120 & 1.253 & 0.720 & 42.53 \\
\hline & 180 & 1.253 & 0.698 & 44.29 \\
\hline & 240 & 1.253 & 0.625 & 50.11 \\
\hline & 360 & 1.253 & 0.624 & 50.19 \\
\hline & 420 & 1.253 & 0.582 & 53.55 \\
\hline & $24 \mathrm{~h}$ & 1.253 & 0.570 & 54.43 \\
\hline \multirow{11}{*}{$\mathrm{V}_{2} \mathrm{O}_{5}^{2-}$} & 5 & 1.135 & 0.999 & 11.98 \\
\hline & 10 & 1.135 & 0.980 & 13.65 \\
\hline & 15 & 1.135 & 0.972 & 14.36 \\
\hline & 30 & 1.135 & 0.880 & 22.46 \\
\hline & 60 & 1.135 & 0.870 & 23.34 \\
\hline & 120 & 1.135 & 0.780 & 31.27 \\
\hline & 180 & 1.135 & 0.725 & 36.12 \\
\hline & 240 & 1.135 & 0.687 & 39.47 \\
\hline & 360 & 1.135 & 0.685 & 39.64 \\
\hline & 420 & 1.135 & 0.675 & 40.52 \\
\hline & $24 \mathrm{~h}$ & 1.135 & 0.669 & 41.05 \\
\hline
\end{tabular}


equilibrated on a water bath shaker at $25^{\circ} \mathrm{C}$ for 24 $\mathrm{h}$ with intermittent shaking. Batch system was used for the activation and modification of the zeolite and ion exchange system. Surfactant HDTMA formed double layer by exchange of its cation with the cation of zeolite thereafter, attraction of its hydrophobic end. After $24 \mathrm{~h}$ zeolite was filtered and washed with deionized water, the surfactant modified zeolite was allowed to dry naturally and kept in a desiccators having calcium chloride under room temperature for the further characterization and sorption runs.

\section{Characterization of Mordenite Zeolite}

Zeolites was characterized by powder $\mathrm{X}$-ray diffraction (RigakuMiniflex) using $\mathrm{Cu}$ - $\mathrm{K} \alpha$ radiation source of wavelength $1.54056 \mathrm{~A}^{\circ}$ and diffrectrograms were recorded in the range $2 \theta=0^{\circ}-70^{\circ}$ at the scanning speed of 1 step/ sec. Powdered XRD were obtained from SICART Gujarat. Powder X Ray diffraction pattern of synthesized zeolite are shown in (Figure1). The main components were $\mathrm{SiO}_{2}, \mathrm{Al}_{2} \mathrm{O}_{3}$, and $\mathrm{Fe}_{2} \mathrm{O}_{3}$ with others found in low concentrations. The structures of zeolites consist of three-dimensional frameworks of $\mathrm{SiO}_{4}{ }^{+}$and $\mathrm{AlO}_{4}{ }^{+}$tetrahedra. $\mathrm{Al}_{2} \mathrm{O}_{3}, \mathrm{Fe}_{2} \mathrm{O}_{3}, \mathrm{CaO}$, and $\mathrm{MgO}$ were analyzed using titrimetric methods and $\mathrm{SiO}_{2}$ was analyzed with a gravimetric method. Morphology of zeolite characterized by Scanning Electron Microscopy (SEM) are shown in (Figure 2). Samples were also scanned using Particle size analysis to determine zeolite particle sizes are shown in (Figure 3). Fourier Transformed Infrared Analysis

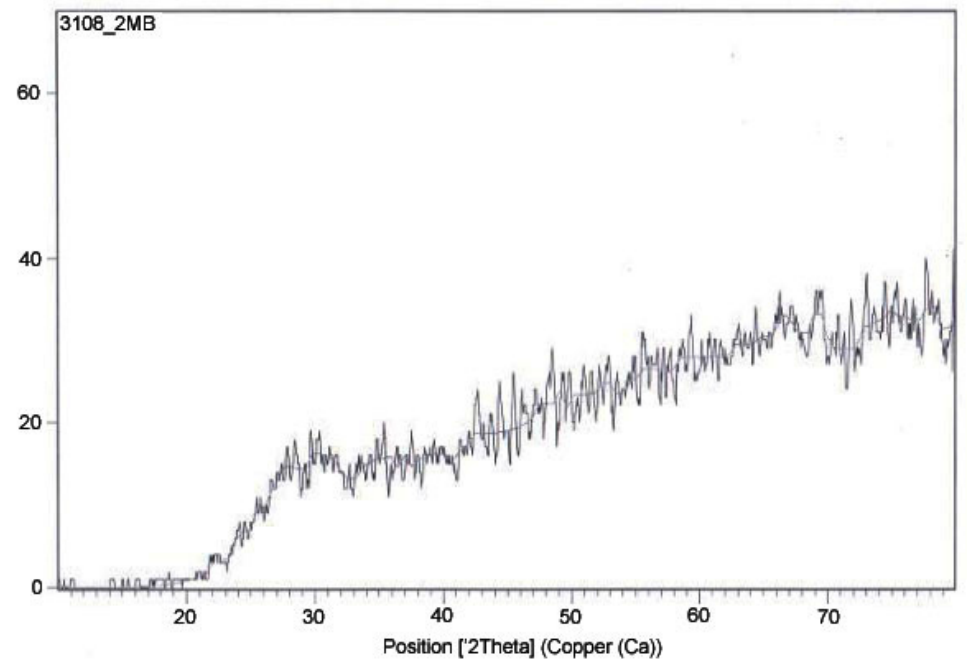

Fig. 1: X-ray analysis
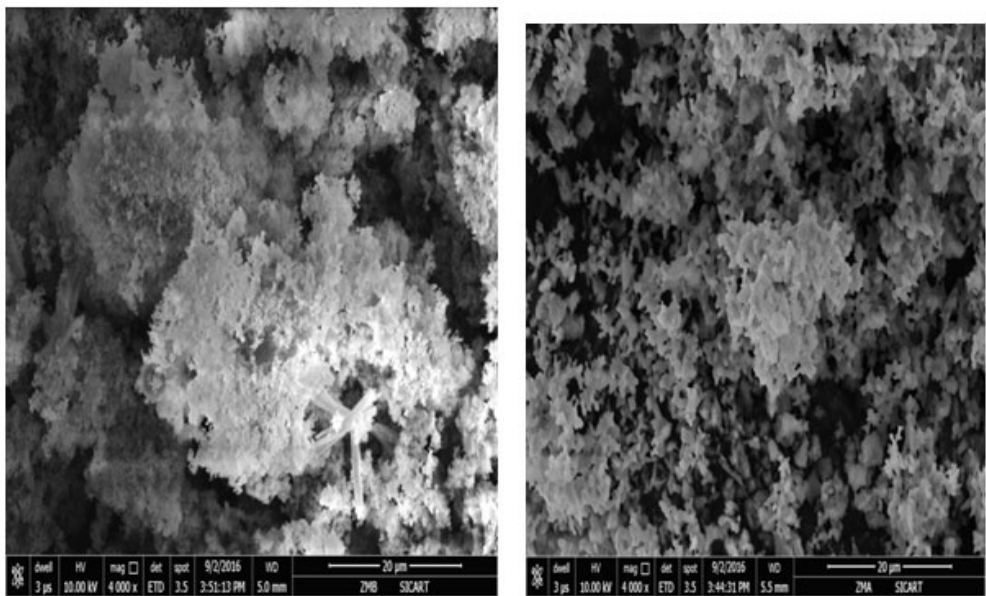

Fig. 2: SEM analysis of (A) Mordenite (B)Modified Mordenite 
(FTIR) spectroscopy is used to investigate the structural features of zeolite. The FTIR spectra of the compound were recorded on a $\mathrm{KBr} 400-4000 \mathrm{~cm}^{-1}$ using Perkin Elmer spectrophotometer and Fourier Transform Infra Red Spectroscopy (FTIR) was performed at room ion of Mordenite temperature, the sample were prepared with $\mathrm{KBr}$ and pressed into wafer/ pellet. Spectra were collected in the mid IR range of $400-4000 \mathrm{~cm}^{-1}$ with resolution of $1 \mathrm{~cm}^{-1}$. Zeolite exhibits a typical infra red spectroscopy pattern. The IR peaks observed for pure zeolite and modified zeolite were compared and found almost similar with each other indicating structure stability of the sample. In contrast modified zeolite has two intense band around $2850 \mathrm{~cm}^{-1}$ and $3500 \mathrm{~cm}^{-1}$ which are assign to symmetric stretching vibration of $\mathrm{C}-\mathrm{CHO}$ of the alkyl chain respectively are shown in (Figure 4).

\section{Reagents}

Inorganic chemicals were supplied by Merck as analytical-grade reagents and deionized water was used. The metal oxoanions studied were chromate $\mathrm{Cr}(\mathrm{VI})$, arsenate $\mathrm{As}(\mathrm{V})$ and vanedate
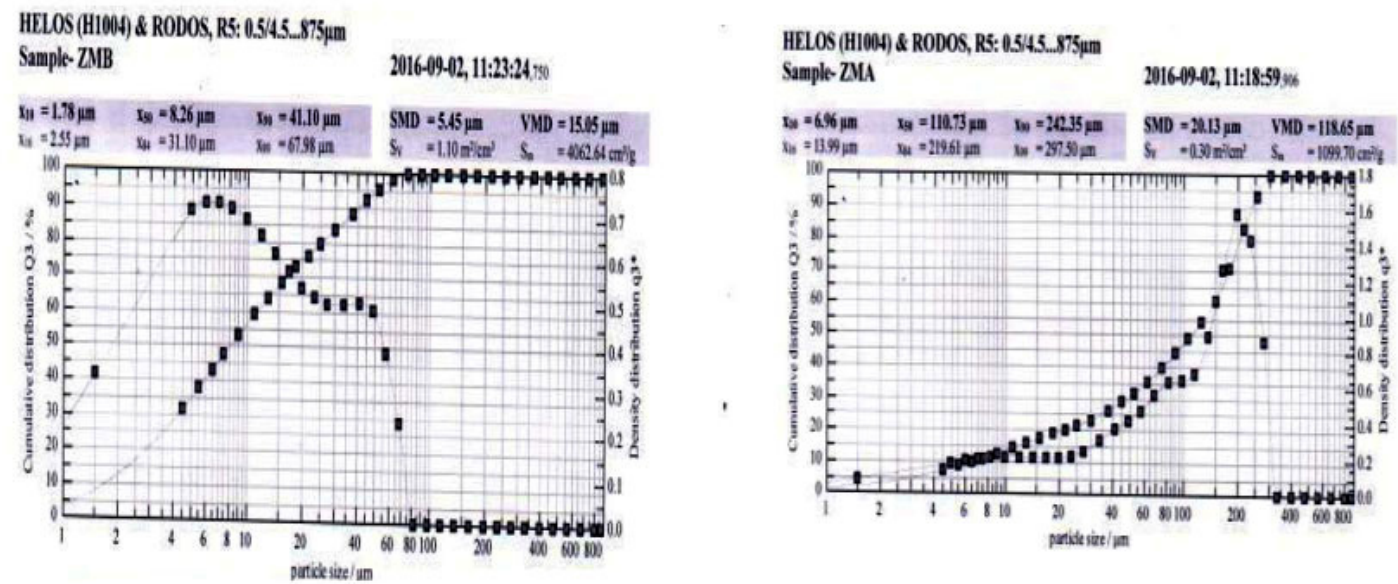

Fig. 3: PSA of (A) Mordenite (B)Modified Mordenite

Table 2:Effect of amount variation of surfactant modified Mordenite on sorption of metal oxoanions

\begin{tabular}{lllll}
\hline Metal oxoanions & $\begin{array}{l}\text { Amount of } \\
\text { exchanger }\end{array}$ & $\begin{array}{l}\text { Initial } \\
\text { concentration }\end{array}$ & $\begin{array}{l}\text { concentration at } \\
\text { equilibrium }\end{array}$ & $\begin{array}{l}\text { Sorption } \\
\%\end{array}$ \\
\hline $\mathrm{CrO}_{4}{ }^{2-}$ & $0.1 \mathrm{gm}$ & 4.446 & 2.609 & 41.32 \\
& $0.2 \mathrm{gm}$ & 4.446 & 2.055 & 53.78 \\
& $0.25 \mathrm{gm}$ & 4.446 & 1.403 & 68.45 \\
& $0.4 \mathrm{gm}$ & 4.446 & 1.087 & 75.55 \\
& $0.5 \mathrm{gm}$ & 4.446 & 1.011 & 77.26 \\
$\mathrm{AsO}_{4}{ }^{2-}$ & $0.1 \mathrm{gm}$ & 1.253 & 0.949 & 24.2 \\
& $0.2 \mathrm{gm}$ & 1.253 & 0.664 & 46.99 \\
& $0.25 \mathrm{gm}$ & 1.253 & 0.638 & 49.07 \\
& $0.4 \mathrm{gm}$ & 1.253 & 0.620 & 50.45 \\
& $0.5 \mathrm{gm}$ & 1.253 & 0.619 & 50.54 \\
$\mathrm{~V}_{2} \mathrm{O}_{5}{ }^{2-}$ & $0.1 \mathrm{gm}$ & 1.135 & 0.747 & 34.14 \\
& $0.2 \mathrm{gm}$ & 1.135 & 0.708 & 37.56 \\
& $0.25 \mathrm{gm}$ & 1.135 & 0.641 & 43.50 \\
& $0.4 \mathrm{gm}$ & 1.135 & 0.520 & 54.12 \\
& $0.5 \mathrm{gm}$ & 1.135 & 0.460 & 59.39 \\
\hline
\end{tabular}


$\mathrm{V}(\mathrm{V})$. Stock solutions of Potassium dichromate Pure $\left(\mathrm{K}_{2} \mathrm{Cr}_{2} \mathrm{O}_{7}\right)$, Sodium arsenate $\mathrm{AR} / \mathrm{ACS}\left(\mathrm{Na}_{2} \mathrm{HAsO}_{4}\right)$, Ammonium Metavanadate $98 \%\left(\mathrm{NH}_{4} \mathrm{VO}_{3}\right)$ were used as sorbate, in deionized water and solutions of various concentrations were obtained by diluting the stock solution. All experiments were carried out in $100 \mathrm{ml}$ volumetric flask at the laboratory ambient temperature of $25 \pm 2^{\circ} \mathrm{C}$.

\section{Batch sorption studies}

The sorption of heavy metals on Surfactant Modified Mordenite zeolite was carried out using the batch method. Batch sorption experiments were conducted using $0.25 \mathrm{~g}$ of sorbent zeolite with

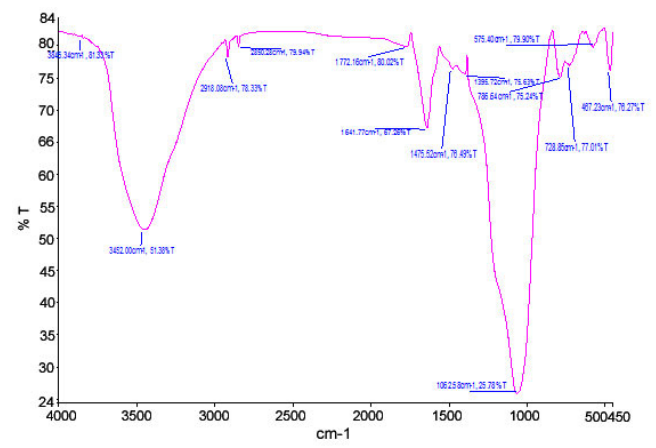

$25 \mathrm{ml}$ of solutions containing heavy metal ions of desired concentrations at constant temperatures (25\%C) in $100 \mathrm{ml}$ conical flask. The flask was sealed and placed on water bath shaker for $24 \mathrm{hr}$ at constant speed 150 RPM and temperatures $(25 \% \mathrm{C})$. After desirable time, solutions containing heavy metals were filtered through Whatman filter paper (No. 42). The exact concentrations of metal ions in filtrate were determined by UV spectrometer (Perkin Elmer spectrophotometer) with regard to its concentration range. The sorption wavelengths used are $540 \mathrm{~nm}$ (Chromate), $840 \mathrm{~nm}$ (Arsenate) and $578 \mathrm{~nm}$ (Vanadate). The efficiency of sorption were calculated using the formula; Sorption

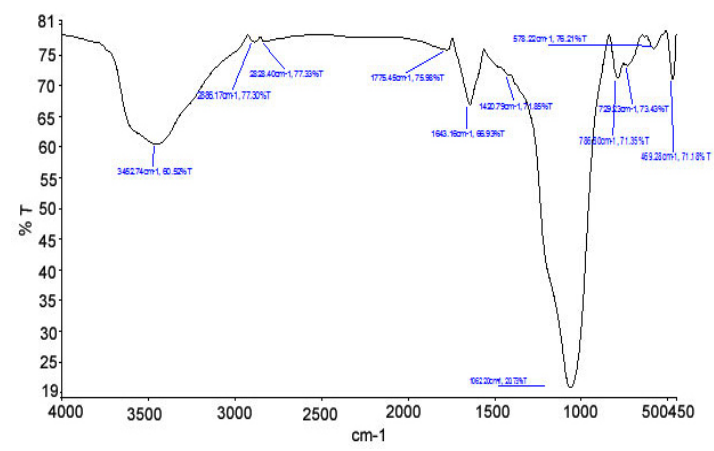

Fig. 4: FTIR analysis of (A) Mordenite (B) Modified Mordenite

Table 3: Effect of metal oxoanion concentration on sorption by surfactant modified Mordenite

\begin{tabular}{lllll}
\hline Metal oxoanions & $\begin{array}{l}\text { Concentration of } \\
\text { exchanger in } \mu \mathbf{g} / \mathbf{m l}\end{array}$ & $\begin{array}{l}\text { Initial } \\
\text { concentration }\end{array}$ & $\begin{array}{l}\text { concentration at } \\
\text { equilibrium }\end{array}$ & $\begin{array}{l}\text { Sorption } \\
\%\end{array}$ \\
\hline $\mathrm{CrO}_{4}{ }^{2-}$ & 50 & 4.446 & 2.127 & 52.15 \\
& 40 & 1.991 & 0.810 & 59.28 \\
& 30 & 1.039 & 0.464 & 55.27 \\
& 20 & 0.612 & 0.248 & 59.46 \\
& 10 & 0.508 & 0.151 & 70.22 \\
& 5 & 0.243 & 0.063 & 74.12 \\
$\mathrm{AsO}_{4}{ }^{2-}$ & 50 & 1.253 & 0.746 & 40.42 \\
& 40 & 0.216 & 0.143 & 33.52 \\
& 30 & 0.190 & 0.109 & 42.16 \\
& 20 & 0.179 & 0.094 & 47.32 \\
& 10 & 0.161 & 0.030 & 81.1 \\
$\mathrm{~V}_{2} \mathrm{O}_{5}{ }^{2-}$ & 5 & 0.158 & 0.017 & 12.11 \\
& 50 & 1.135 & 0.997 & 13.65 \\
& 40 & 1.080 & 0.932 & 25.00 \\
& 30 & 0.701 & 0.525 & 25.37 \\
& 20 & 0.580 & 0.432 & 34.57 \\
& 10 & 0.592 & 0.387 & 44.82 \\
\hline
\end{tabular}


$\%=[(\mathrm{Ci}-\mathrm{Ce}) / \mathrm{Ci}] \times 100$, where $\mathrm{Ci}$ and $\mathrm{Ce}$ are the initial and equilibrium concentration $(\mu \mathrm{g})$ of metal ions in solution, respectively. The effects of metal ion concentration, sorption dose, contact time and temperature were estimated.

\section{Sorption kinetic}

Batch kinetic experiments were performed by mixing $0.25 \mathrm{~g}$ sorbent to each conical flask with $25 \mathrm{~mL}$ of metal ion solution having strength of $50 \mu \mathrm{g} / \mathrm{ml}$ at room temperature (i.e. $25 \pm 2^{\circ} \mathrm{C}$ ). A series of such conical flasks were then shaken at a constant speed of $150 \mathrm{rpm}$ in a water bath shaker and samples were collected at different Preset time intervals. (Table 1) provides the experimental outline for the kinetic experiments.

\section{RESULTS AND DISCUSSION}

\section{Effect of contact time on sorption}

In order to accomplish the kinetics study the effect of contact time experiments on Chromate, Arsenate, vanadate sorption by surfactant modified mordenite, was carried out with $50 \mu \mathrm{g} /$ $\mathrm{ml}$ concentration., ranging from $5 \mathrm{~min}$. to $24 \mathrm{~h}$ are shown in (Table1). The plots of Chromate, Arsenate, vanadate sorption percentage against contact time are shown in (Figure). which indicate that Chromate, Arsenate, vanadate sorption increases with time and attain equilibrium in 6-7 hours. This trend emphasizes that the time of sorption have an important effect on the sorption efficiency which increases significantly with increasing contact time with metal oxoanions solution. This is the consequence the ability of

\section{Time (min)}

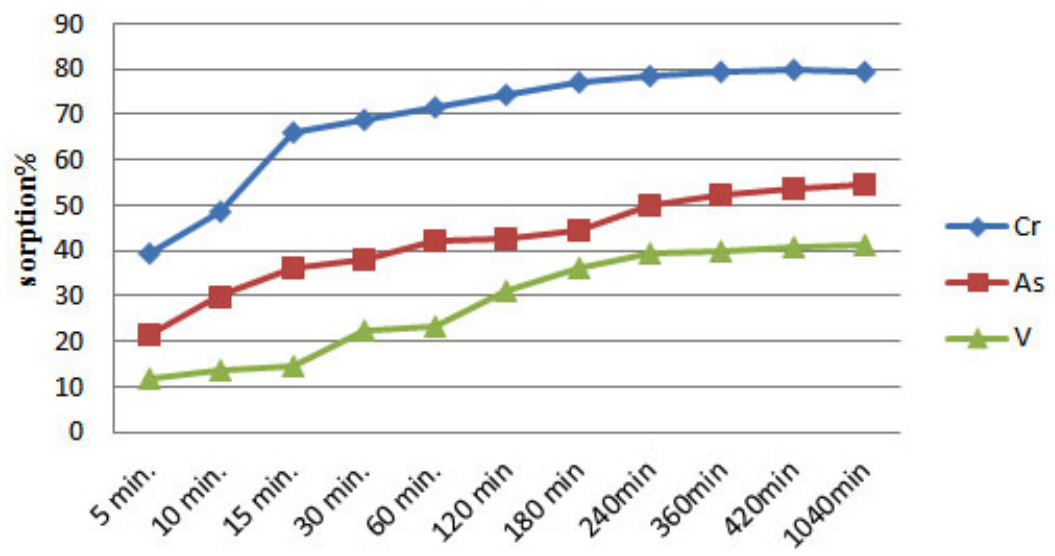

Fig. 5: Effect of contact time on sorption

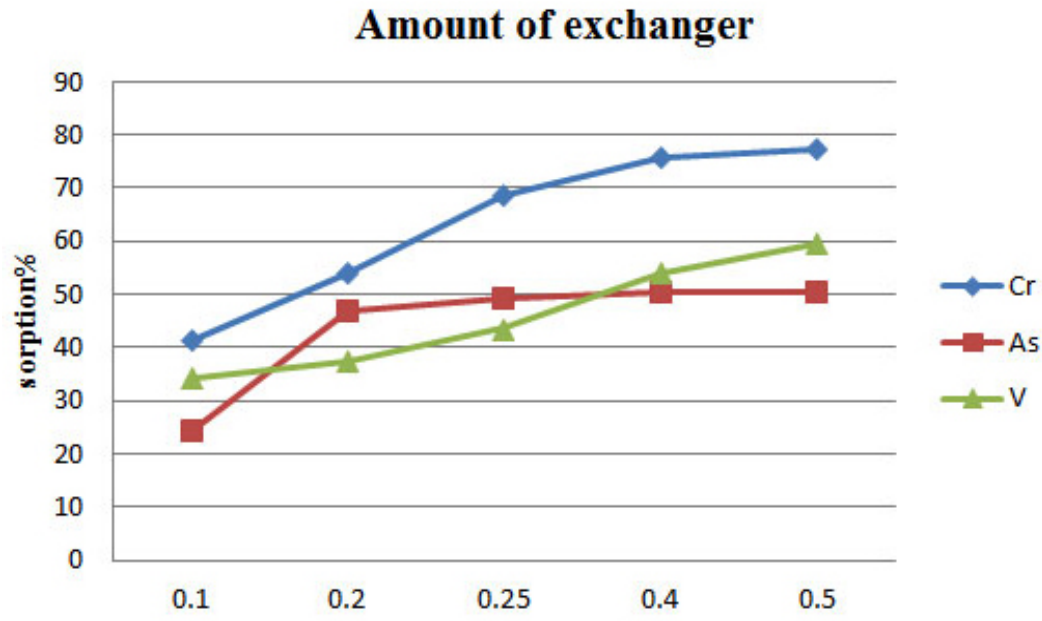

Fig. 6: Effect of sorbent dose on sorption 


\section{Concentration of metal oxoanion}

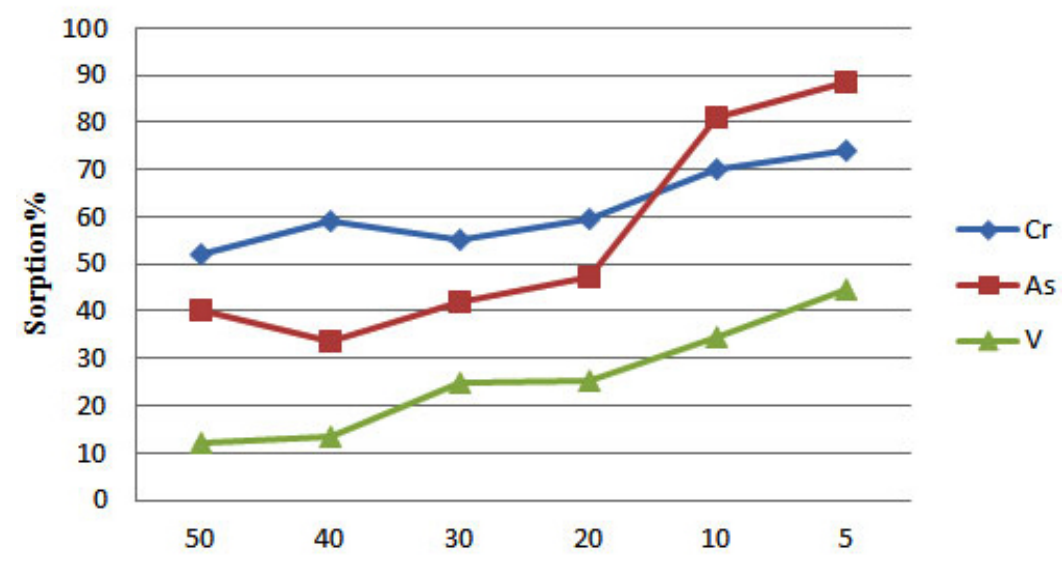

Fig. 7: Effect of metal concentration on sorption

surfactant modified mordenite to sorb Chromate, Arsenate, vanadate is due to the anion exchange at the positive sites brought about by the reserved charged resulting from the HDTMA double layer on to zeolite sutface. The (Figure 5) suggest that surfactant modified Mordenite is efficient in removing Chromate, Arsenate, Vanadate (V) ions from aqueous solution.

\section{Effect of sorbent dose on sorption}

To determine the effect of sorbent dosage on sorption, the sorbent dose were varied from 0.1 gm to $0.5 \mathrm{~g}$ while Chromate, Arsenate, Vanadate metal ion concentration were kept constant as 50 ig/ $\mathrm{ml}$. Data obtained by analysis is given in (Table 2). As expected the percentage of Chromate, Arsenate, Vanadate sorption increased with increasing surfactant modified Mordenite. As seen from (Figure 6) the increase in Chromate, Arsenate, Vanadate sorption with sorbent dose can be attributed to increased surface area and the sorption sites. The data shows that with increase in weight of exchanger from 0.1 to $0.5 \mathrm{~g}$ sorption percentage increases.

\section{Effect of metal concentration on sorption}

Variation in metal oxoanion concentration has been analysed as an important factor in sorption. By changing the concentration of Chromate, Arsenate, Vanadate from $50 \mu \mathrm{g} / \mathrm{ml}$ to $5 \mu \mathrm{g} / \mathrm{ml}$. Results of the analysis is shown in (Table 3 ). It was found that sorption percentage decreases this shown in (Figure 7). This is due to the increasing number of metal ion that compete for a infinite number of binding sites on the sorbent surface. After reaching maximum sorption any further increase in sorbent concentration only saturates the binding sites, therefore decreasing the percentage of sorbed all metal oxoanions.

Moreover, higher initial sorbent concentration provides higher driving force to overcome all mass transfer resistance of the metal ion from the aqueous to the solid phae resulting in higher probability of collision between all metal oxoanions and the active sites.

Consequently in lower concentration there are sufficient active sites which the sorbent could easily occupy, hence all metal oxoanions are left unsorbed in solution due to saturation of binding sites.

\section{CONCLUSIONS}

Based on the present investigation, it could be concluded that some low cost materials Like Mordenite zeolite can be used as sorbent efficiently in the removal of heavy metal as oxoanions $\left(\mathrm{CrO}_{4}{ }^{2-}\right.$, $\mathrm{AsO}_{4}{ }^{3-a n d ~} \mathrm{~V}_{2} \mathrm{O}_{5}{ }^{2-}$ from aqueous solutions. The present work deals with the synthesis, surface modification and characterization of analogue of modified mordenite zeolite. Based on model experiments, it was found that Modified Mordenite zeolite could be used for binding of oxoanion in the process of ion exchange that was identified as the dominating mechanism of the process (beside physical sorption). In this process, oxoanions bind to cationic groups on zeolite surface. The reaction parameters such as 
reaction time, amount of modified mordenite zeolite and concentration of various metal oxoanions were optimized.

It was observed that after modification the pore size of zeolite becomes larger and facilitate the reactant to get entered into it and promoted the sorption. Experimental results showed that the best equilibrium time for sorption were 6-7 hours. It was observed that after modification the competitive capacity achieved through functionalization this material can be considered as a potential candidate for treatment of Chromate, Arsenate, vanadate from contaminated wastewater. Studies also reveal that modified Mordenite shows maximum sorption efficiency up to $79 \%$ for chromate among the ions study.

Sorption with SMMZ found to be rapid, reversible, first order reaction. Equilibrium was reached after $7 \mathrm{hr}$. The removal of heavy metal as oxoanions was sorbent and concentration dependent as the sorption capacity increases with increasing the sorbent amount in the solution. The metal oxoanions (Chromate, Arsenate, Vanadate ) were showed different behaviors towards sorption on surface Modified mordenite zeolite with increasing the initial concentration of the metal ions. This investigation also showed Modified mordenite zeolite to be suitable sorbent for removing the Chromium, Arsenic and Vanadium as oxoanions. Laboratory tests on Chromate, Arsenate, Vanadate removal from Waste Water showed the potential applicability of this method in the treatment. The experimental studies showed that Modified Mordenite Zeolite could be used as an alternative, inexpensive and effective material to remove high amounts of toxic heavy metals from wastewater.

\section{ACKNOWLEDGMENTS}

Authors are thankful to MPCST, Bhopal for providing financial support to carry out the research work and ITM University, Gwalior M.P. for providing Infra Structure facility. Support of SICART, Gujarat and SAIF Punjab University Chandigarh for the characterization of the synthesized material and analysis of product is also acknowledged.

\section{REFERENCES}

1. Muller, K.J.; Kreysa, G.; Dechema Monographien 1985,98, 367.

2. Jothinayagi, N.; Anbazhagan, C. AmericanEurasian J. Sci. Res. 2009,4, 73-80.

3. Shafaghat, A.; Salimi, F.; Valiei, M.; Salehzadeh, J.; Shafaghat, M.;.2012, 11, 852-855.

4. Devaprasath, P. M.; Solomon, J. S. J. Appl. Sci. Environ.Sanit. 2007, 2, 77-83.

5. Al-Subu, M. M.; Salim, R.; Abu-Shqair, I.; Swaileh, K. M. Int. Contam. Ambient. 2001, 17, 91-96.

6. Mehrasbi, M. R.; Farahmand, Kia Z. J. Health . Environ. 2008, 1, 57- 66.

7. Uzun, I., Guzel, F. Turk. J. Chem. 2000.24, 291- 297.

8. Nieboer, E.; Jusys, A.A. Biologic chemistry of chromium, In: Nriagu, J.O., Nieboer, E., (Eds.), Chromium in natural and human environments. John Wiley and Sons, Inc., New York,1988, 21-81.

9. Stasicka, Z.; Kotas, J.; Environ. Pollut.
2000, 107, 263-283.

10. XiY.Synthesis, Characteristion and Application of Organoclays. Ph.D. thesis, Queensland University of Technology. 2006.

11. Dutta, A.; Chaudhuri, M. Aqua. 1991.,40, 25.

12. Pontius, F.W.; J Am Water Works Assoc.1994. $86,6$.

13. Hernandez-Ramirez , O.; Holmes, S.M.; J. Mater. Chem. 2008, 18, 2751-2761

14. Breck, D.W. Zeolite Molecular Sieves: Structure, Chemistry, and Use. John Wiley \& Sons, New York. 1974.

15. Pabalan, R. T.; Bertetti, F. P; Nat. Zeolites. 2001, 45, 453-518.

16. Li, Z.; Bowman, R.S. Environ. Eng. Sci.1998, 15, 237-245.

17. Leyva-Ramos,R.; Jacobo-Azuara, A.; TorresRivera, O. L.; Guerrero-Coronado, R. M.; Berber-Mendozaa M. S.; Alonso-Davila, Pedro. J. Environ. Eng. Manage 2008,18, 311-317. 